\title{
LA IGUALDAD Y SU CARÁCTER TRIFONTE: ¿PRINCIPIO, VALOR, DERECHO? FORMAS DE VULNERACIÓN
}

\author{
EQUALITY AND ITS “THREE-SOURCED” NATURE: PRINCIPLE VALUE, RIGHT? \\ FORMS OF INFRINGEMENT
}

\section{Resumen}

Lic. Sudis María Velázquez Borges*

Hoy es un hecho que parte importante de los juicios de justicia que realiza el ciudadano común se fundamentan, en mayor o en menor grado, en la idea de la igualdad; transformándose con ello en una herramienta evaluativa general. Al constituir uno de los parámetros fundamentales del pensamiento social, jurídico y político la igualdad intenta encontrar una justificación como derecho, principio y valor a proteger. Sobre la base de realizar un sucinto recuento de algunas de las posiciones teóricos-doctrinales acerca del valor trifonte de la cual está investida esta categoría, se pretende, dejar manifiesto las diferentes dimensiones a las cuales se expande dicha concepción, así como las diversas formas en que puede ser quebrantada la igualdad no solo en el ámbito formal sino el material.

Sumario: 1. Sentido y alcance de la expresión "igualdad"; 2. Principio de Igualdad; 3. Derecho de Igualdad; 4. Igualdad como valor; 5. Derecho Comparado; 6. Formas de Vulneración de la Igualdad; 7. Reflexiones finales.

\begin{abstract}
Today it is an undisputed fact that an important part of the judgments of justice, that the ordinary citizen takes, are based, to a greater or lesser extent, on the idea of equality; thereby becoming a general evaluative tool. For being one of the fundamental parameters of social, legal and political thought, equality tries to find a justification as law, principle and value to protect. On the basis of making a brief account of some of the theoretical and doctrinal positions on "three-sourced" value of which is vested in this category, intended, make it manifest different dimensions to which this concept is expanded, and the various ways in which can be broken equality not only in the formal setting but the material too.
\end{abstract}

Summary: 1. Meaning and scope of the term "equality"; 2. Principle of Equality; 3. Right of Equality; 4. Equality as a value; 5. Comparative Law; 6. Forms of Violation of Equality; 7. Final thoughts.

\section{Introducción}

El concepto de igualdad desde sus inicios formó parte del acervo cultural del pensamiento occidental, procede de Platón y, especialmente, de Aristóteles ${ }^{1}$. Cada sociedad, en su respectiva época histórica, ha dotado de contenido concreto el concepto arquetípico de igualdad; bajo él se han sucedido diversas concepciones históricas de la igualdad, algunas de ellas no sólo diferentes sino también contradictorias. La igualdad constitucional en la actualidad, posee una triple condición de valor superior del ordenamiento jurídico, de

\footnotetext{
*Universidad de Granma, Bayamo-Cuba, Cuba.
} 
principio, y de derecho fundamental; aspectos que serán analizados en el presente artículo, realizándose un estudio preliminar de los significados que se le ofrece a tal concepto, en virtud de la trascendencia jurídica de la igualdad como elemento estructural de nuestro Derecho, cuestiones de suma importancia que deben ser consideradas por el legislador, la administración pública y los jueces a la hora de impartir justicia, y por ende evitar las numerosas formas de vulneración que sufre tanto la igualdad formal y como material.

La igualdad entronca con su trascendencia como orientación y directriz de nuestro ordenamiento jurídico. "La idea de igualdad pasa por ser uno de los parámetros fundamentales del pensamiento social, jurídico y político de nuestro tiempo. Su importancia como idea regulativa básica no va regularmente acompañada ni por la claridad de formulación ni por la precisión de su sentido y límites. Suele ser, más bien, un concepto muy discutido en torno al cual surgen frecuentes desacuerdos prácticos y pugnas teóricas importantes" (LAPORTA, 1985, p.3).

El concepto de igualdad, desde el punto de vista normativo, es un concepto indeterminado que requiere de un esfuerzo creativo importante por parte del intérprete al momento de juzgar si una determinada norma o situación pueden lesionarlo. Si acudimos al Diccionario de la Real Academia Española podemos encontrar que el vocablo "igualdad" proviene del latín aequalitas y tiene dos significados generales; significando: conformidad de algo con otra cosa en naturaleza, forma, calidad o cantidad, así como: correspondencia o proporción que resulta de muchas partes que uniformemente componen un todo.

Para el ámbito de las ciencias sociales es importante recordar que cuando utilizamos el término igualdad normalmente lo hacemos en un sentido normativo y no descriptivo; es decir, cuando decimos que dos personas son iguales ante la ley lo que en realidad queremos decir es que la ley debería tratarlas como iguales, porque de otra manera esa ley estaría violando tal o cual artículo de la Constitución o de un tratado internacional. Perspectiva normativa a la que se afilia la autora, pues como es obvio, no hay dos personas completamente iguales. Desde una perspectiva política, el estudio de la igualdad intenta encontrar su justificación como valor a proteger, y como argumentación para elegir entre los distintos tipos de igualdad que existen en la realidad. 
Tiene razón Francisco Rubio Llorente cuando afirma que: "la igualdad designa un concepto relacional, no una cualidad de una persona, de un objeto (material o ideal), o de una situación, cuya existencia pueda ser afirmada o negada como descripción de esa realidad aisladamente considerada; es siempre una relación que se da al menos entre dos personas, objetos o situaciones. Es siempre el resultado de un juicio que recae sobre una pluralidad de elementos (en el caso límite, al menos una dualidad), los "términos de la comparación", entre los cuales debe existir al mismo tiempo alguna diversidad, aunque sólo sea espacial o temporal, pues de otro modo, como es obvio, no cabría hablar de pluralidad. La diferencia, al menos numérica, entre los elementos comparados es condición de posibilidad del juicio de igualdad" (LLORENTE, 1993, p.640). En tal sentido es dable considerar que ni en la naturaleza ni en la sociedad existe lo igual, sino, precisamente, lo diverso. Por tanto, la igualdad no es una realidad objetiva o empírica anterior al derecho, que éste sólo tenga que percibir, sino que toda constatación jurídica de la igualdad implica siempre un juicio de valor, un proceso de abstracción que depende de la elección de las propiedades, criterios o rasgos considerados como relevantes entre los que se compara.

Por otro lado para Douglas Rae la igualdad es un nombre común a muchos conceptos diferentes. Frente a esta posición Peter Westen ha defendido que mientras existen diversas concepciones de igualdad ${ }^{2}$, su concepto, sin embargo, es sólo uno. Según este criterio, todas las concepciones de igualdad presuponen un concepto común, que comprenden elementos esenciales y constantes.

Para Hans Kensel "el principio de igualdad significa que sólo los que son iguales deben ser tratados de modo semejante" (MIGUEL, 2003, p.46). Significado ambiguo de la noción de semejanza, que permite atender tanto a los aspectos de identidad como a los de diferenciación. Lo semejante, antes de cualquier especificación, puede ser igual pero también puede ser diferente.

Sin embargo Juan María Bilbao Ubillos y Fernando Rey Martínez ven a la igualdad como un juicio comparativo para medir la legitimidad o ilegitimidad de una desigualdad jurídica de trato entre un conjunto de individuos dado, que se hallan en una situación análoga, semejante o comparable, respecto de un criterio previamente determinado (UBILLOS; MARTÍNEZ, 2003, p.107). 


\section{Principio de Igualdad}

El Derecho al ser más que normas y valores, lo integran además un conjunto de principios que están en su substrato o jurídicamente definidos, que sirven de pauta creadora, interpretativa e integradora, y que su observancia es esencial a fin de permitir la realización de los valores de justicia, igualdad, certeza y seguridad entre otros.

Desde sus orígenes la igualdad como principio no ha sido identidad de trato a todos, sino únicamente para los que tenían similares características; y diferente trato para aquellos que tienen distinciones debidamente reconocidas por el derecho; a estos últimos se les dará trato distinto. Por lo tanto sería el primer desarrollo del principio de igualdad, en un intento por definirlo. Una igualdad que reconoce que no todos somos iguales y que tratará a los individuos dependiendo que se adapten a las clasificaciones que el propio Derecho realiza.

Luego el principio de igualdad fue desarrollándose desde un punto de vista objetivo (la norma en sí). Esto es, la norma prevé en su hipótesis una abstracción generalizada que "resuelve todos los casos idénticos de la misma manera", sin que esta igualdad objetiva de la norma no reconozca la desigualdad tanto de los sujetos a los que se va dirigida o aplica, inclusive a los que están en una misma categoría, también reconociendo las variadas situaciones que debe atender la norma y que la abstracción no contiene textualmente.

También se ha desarrollado el principio atendiendo a los sujetos, esto es, haciendo énfasis en la igualdad de los individuos ante el Derecho; ante la norma jurídica y la posibilidad de exigir como derecho y garantía fundamental la igualdad de trato ante la norma. Se ha desarrollado como derecho humano o fundamental o constitucional en las diversas constituciones de los Estados.

El principio de igualdad como derecho fundamental, humano y constitucional también se ha desarrollado transversalmente en todas las áreas del derecho y aplicado a cada uno de los otros derechos fundamentales. Cada área y en especial aquellas de mayor trascendencia para la sociedad (como los otros derechos humanos o fundamentales o constitucionales) lo han desplegado en formas prácticas, con la intención de materializar la igualdad de los sujetos en lo que se refiere en el acceso a servicios u otros derechos; por R. Fac. Dir. UFG, v. 38, n. 1, p. 119 - 141, jan. / jun. 2014 
ejemplo en referente a educación, salud, buen vivir, vivienda, trabajo, dignidad, justicia, participación social y política.

Con relación al principio de igualdad podemos señalar momentos particulares, a partir de los cuales va desarrollándose con mayor fuerza. Por ejemplo será a partir de 1789, con la Revolución Francesa, su principal "catalizador" para ser incorporado en las normas jurídicas. Con esta Revolución la sociedad actúo frente al absolutismo monárquico, lo venció y proclamó, entre otros los principios del nuevo Estado: libertad, fraternidad e igualdad de los ciudadanos. Esta etapa ya tenía como antecedente el desarrollo intelectual y jurídico de autores como: Rousseau, Voltaire o Montesquieu (VÁSCONEZ, 2011, p.421).

Su presencia en la Declaración de los Derechos del Hombre que se da en ese mismo año 1789, permitió que fuera reconocido e incorporado en la Constitución francesa de 1791. A su vez esta influencia, en la norma constitucional francesa, provocó que fuera tomado por otros regímenes. Aparecerá como derecho en el Estatuto Fundamental de la Monarquía de Saboya (Estatuto Albertino) el 4 de marzo de 1848, para regir en el reino conformado por los territorios de Cerdeña, Chipre y Jerusalén (lo que actualmente es Italia). Este estatuto se constituyó en su Ley Fundamental y fue reemplazado en 1948 por la Constitución Italiana. La esencia de esta influencia es que se considerará al conglomerado de los ciudadanos "jurídicamente iguales". Así este concepto de igualdad se va diseminando en todas las constituciones de Europa.

Sin embargo, será a partir del 10 de diciembre de 1948, fecha en la que la Asamblea de las Naciones Unidas proclamó la Declaración Universal de los Derechos Humanos, en que este principio de igualdad de derechos toma otro momento de aceptación general, aplicación y desarrollo en las diversas áreas jurídicas. La Declaración Universal de los Derechos Humanos, en su "preámbulo" explica que en consideración a los "derechos iguales" de los miembros de la familia humana, la dignidad de las personas, así como bajo la consideración que existe una "igualdad de derechos entre hombres y mujeres" dispone en su contenido que los seres humanos nacen iguales en dignidad y derechos, así como son iguales ante la ley, tanto para no hacer distinción así como para la protección de ellos ${ }^{3}$.

Constituido como Derecho fundamental de los individuos (derecho humano) la igualdad aparece consolidando varias características a la vez: como derecho y como principio. 
La igualdad no es definible pura y simplemente en la ciencia jurídica, sino que, es un concepto amplio que como derecho fundamental se va a ir determinando su contenido "limitado, ilimitable y delimitable" en función de lo previsto y desarrollado en las propias normas constitucionales, las normas y principios y valores relacionados al mismo, así como en todo lo que se ha desarrollado en los sistemas de protección de Derechos Humanos.

Pero por otra parte para la teoría de los derechos fundamentales, lo más importante es la distinción entre reglas y principios (ALEXY, 1993, p.81). Sin ella, no puede existir una teoría adecuada de los límites, ni una teoría satisfactoria de la colisión y tampoco una teoría suficiente acerca del papel que juegan los derechos fundamentales en el sistema jurídico. Esto es un elemento básico de la dogmática del derecho de igualdad. Constituyendo la distinción entre reglas y principios uno de los pilares fundamentales de la teoría de los derechos fundamentales.

No pocas veces, las normas iusfundamentales son llamadas "principios". Con mayor frecuencia se subraya el carácter de principios de las normas de derechos fundamentales de una manera no tan directa. Tanto las reglas como los principios son normas porque ambos dicen lo que debe ser. Ambos pueden ser formulados con la ayuda de las expresiones deónticas básicas del mandato, la permisión y la prohibición. Los principios, al igual que, reglas, son razones para juicios concretos de deber ser, aun cuando sean razones de un tipo muy diferente. La distinción entre reglas y principios es pues una distinción entre dos tipos de normas.

Numerosos son los criterios propuestos para la distinción entre reglas y principios. El de generalidad es el más frecuentemente utilizado. Los principios son normas de un grado de generalidad relativamente alto, y las reglas normas con un nivel relativamente bajo de generalidad. Las normas que gozan de un alto grado de generalidad se refieren a todos los individuos de una clase abierta. Lo opuesto a la norma universal es la norma individual. El concepto opuesto de generalidad es el de especialidad.

Según Robert Alexy el punto decisivo para la distinción entre reglas y principios es que los principios son normas que ordenan que algo sea realizado en la mayor medida posible, dentro de las mayores posibilidades jurídicas y reales existentes. Por lo tanto, los 
principios son mandatos de optimización, que están caracterizados por el hecho de que pueden ser cumplidos en diferentes grado y en la medida debida de su cumplimiento no sólo depende de las posibilidades reales sino también de las jurídicas. El ámbito de las posibilidades jurídicas es determinado por los principios y reglas opuestos. En cambio, las reglas son normas, que sólo pueden ser cumplidas o no. Si una regla es válida, entonces de hacerse exactamente lo que ella exige, ni más ni menos. Por lo tanto, las reglas contienen determinaciones en el ámbito de lo fáctico y jurídicamente posible. Esto significa que la diferencia entre reglas y principios es cualitativa y no de grado. Toda norma es o bien una regla o un principio (ALEXY, 1993, p.87).

Por otra parte Francisco J Laporta expresa que un principio es un enunciado normativo de carácter muy general o abstracto, pero que, dejando a un lado esa generalidad o abstracción, no tiene una estructura diferente de la de la norma concreta. Sólo hay entre ambas diferencias de grado o determinación, no diferencias de clase. Los principios y las normas pueden relacionarse entre sí de varios modos. "Podría decirse que las normas concretas pueden inferirse a partir de principios, pero es más completo expresarlo diciendo que, dada la aceptación de un principio, una norma completa puede justificarse apelando a ese principio; es decir, los principios funcionan como razones justificadoras de las normas particulares y concretas que son especificaciones suyas. Cuando una norma se justifica apelando a un principio, se suele decir que satisface ese principio" (LAPORTA, 1985, p.1).

Es muy importante tener en cuenta que la satisfacción de un principio se produce con frecuencia, no por una norma aislada, sino a través de un conjunto coherente de normas tomado como un todo, independientemente de que alguna de sus normas no sea una expresa concreción de ese principio. En este caso el principio operaría, no sólo como justificación de esas normas, sino también como racionalización o definición del conjunto, es decir, dotando al conjunto de un sentido unitario.

Como bien expresa Robert Alexya través de las disposiciones iusfundamentales, se estatuyen dos tipos de normas, es decir, las reglas y los principios, criterio al que se afilia la autora ya que el mismo fundamenta el carácter doble de las disposiciones iusfundamentales y por ende el valor trifonte de la igualdad. Para Laporta "el principio de igualdad no son sino normas universales que operan como razones justificativas de las normas concretas de igualdad" (LAPORTA, 1985, p.7). 
El principio de igualdad representa uno de los pilares de toda sociedad bien organizada y de todo Estado Constitucional (PULIDO, p.1). El principio de igualdad se proyecta también en el momento de la aplicación de la ley (no sólo en el contenido de la norma, en la fase de configuración normativa): se ha de aplicar por igual a todos aquellos que se encuentren en la misma situación, con independencia de las condiciones personales o sociales de sus destinatarios. No se puede aplicar con más rigor o benevolencia en atención a circunstancias a las que el ordenamiento no concede relevancia. No caben las decisiones ad personam (sólo pueden tenerse en cuenta los criterios de diferenciación entre personas o situaciones contenidos en la propia norma). Este principio vincula, por tanto, a los órganos administrativos y jurisdiccionales, encargados de dicha aplicación. El principio de igualdad tiene, pues, una dimensión que se proyecta en la continuidad de la aplicación de la ley por los órganos judiciales, vedando una interpretación voluntarista o arbitraria de la norma.

Para concluir esta concepción de la igualdad como principio Francisco J. Laporta expresa que la igualdad no está determinada por hechos sino que es simplemente es un producto de la estructura normativa de la sociedad. Por un lado el enfoque es normativo en cuanto que opera siempre sobre la base de que la idea de igualdad es un "principio" y no una descripción genérica de la realidad (LAPORTA, 1985, p.1). En igual posición se encuentra Peter Singer al expresar que es un "principio" ético básico, no una aserción de hecho (VÁSCONEZ, 2011, p.421).

\section{Derecho de Igualdad}

En virtud de la asunción y generalización de las premisas del Estado social, la forma de entender los derechos fundamentales ha cambiado. No sólo se ha ampliado el catálogo de aquellos derechos que se consideran como fundamentales, de modo tal que han pasado a entenderse como tales el derecho a la sindicación, a la huelga, a la salud o a la educación, sino que además algunos derechos, como la igualdad, han comenzado a interpretarse de modo más inclusivo, ampliando con ello lo que se consideraba como fundamental.

Es así que no debe resultar extraño que hoy buena parte de la doctrina interprete el derecho fundamental a la igualdad, como un principio general de igualdad en sentido amplio, R. Fac. Dir. UFG, v. 38, n. 1, p. 119 - 141, jan. / jun. 2014 
en virtud del cual se le puede exigir al Estado y a otros particulares, no sólo que no diferencien a las personas, grupos de personas o estados de cosas, sino que además se tomen las medidas necesarias para que las desigualdades que existen de hecho desaparezcan. Esto hace que el derecho fundamental a la igualdad sea considerado por muchos como un derecho de doble faz, cuyo cumplimiento se puede exigir tanto negativa como positivamente.

Como bien expresa el autor Carlos Bernal Pulido, como derecho la igualdad atribuye al individuo (el sujeto activo) el derecho de exigir del Estado (el sujeto pasivo) el cumplimiento de los mandatos que se derivan del principio de igualdad. En todo caso, el principio y el derecho a la igualdad se proyectan en dos niveles distintos: la igualdad ante la ley y la igualdad en la ley. El primer nivel se refiere a la eficacia vinculante de los mandatos de la igualdad en la aplicación administrativa y jurisdiccional de la ley y en las relaciones entre particulares. El segundo nivel, en cambio, alude al carácter definitorio de la igualdad como derecho fundamental, es decir, a su eficacia vinculante frente al Legislador.

Por otra parte Robert Alexy plantea la estructura de los derechos de igualdad como derechos subjetivos. El mismo hace una distinción de tres tipos de derechos que resultan de la máxima general de la igualdad: "los derechos de la igualdad definitiva abstracta, los derechos de igualdad definitivos concretos y los derechos de igualdad prima facie abstractos" (ALEXY, 1993, p.415).

Dos son los derechos de igualdad definitivos abstractos: el derecho a la igualdad de tratamiento cuando no existe ninguna razón suficiente para la permisión de un tratamiento desigual y el derecho a ser tratado desigualmente cuando existe una razón suficiente para que esté ordenado un tratamiento desigual.

Miguel Carbonel sustenta la teoría de Rober Alexy al expresar que igualdad es el derecho de todos los seres humanos a ser iguales en su dignidad, a ser tratados con respeto y consideración y a participar con base igualitaria con los demás en cualquier área de la vida civil, cultural, política, económica y social. Todos los seres humanos son iguales ante la ley y tienen derecho a una misma protección y garantía ant la ley.

a) Igualdad en la ley. Se trata de un mandato dirigido principalmente al legislador, para que regule las diversas situaciones sin hacer discriminaciones odiosas. 
b) Igualdad ante la ley. Es propia de la aplicación de la ley y, consecuentemente, es una regla dirigida y aplicada fundamentalmente por los jueces. ${ }^{4}$

c) Igualdad por la ley. El Estado corrige ciertas desigualdades de hecho a través de la ley.

Siguiendo con lo expuesto, encontramos que el derecho de igualdad actúa con eficacia jurídica en tres niveles distintos: primero, conlleva una exigencia de igualdad en la ley que torna a este derecho en un límite obligatorio para la actividad del legislador; segundo, su eficacia se manifiesta en la aplicación de la ley, en este plano actúa como condición exigible ante los órganos del Estado que aplican el derecho para que no haya discriminación.

Sin embargo Javier Pérez Royo plantea que la igualdad constitucional no afirma que los individuos son iguales y no pretende que lo sean de manera real y efectiva. Lo que la igualdad constitucional afirma es que los individuos son diferentes y lo que persigue es posibilitar primero que las diferencias personales se expresen como diferencias jurídicas y garantizar después el ejercicio del derecho a tales diferencias. Por tanto la razón de ser de la igualdad es el derecho a la diferencia. No que todos los individuos sean iguales, sino que cada uno tenga derecho a ser diferente. Justamente por esto Pérez Royo se opone a la tesis de que la igualdad es un derecho, al expresar que la igualdad ni es ni puede ser un derecho. "El derecho a la igualdad sería contradictorio con la condición individual del ser humano y, en consecuencia, ni existe ni puede existir. Aunque algún constituyente, en un arrebato de locura, quisiera afirmar que los individuos son iguales y quisiera configurar la igualdad como un derecho a ser iguales, no podría conseguirlo" (ROYO, 2005, p.277). En este sentido la igualdad no puede ser confundida como derecho sino repugna a la condición individual del ser humano, ya que el ejercicio de los derechos es una permanente manifestación de nuestra individualidad, es decir, no aquello en que somos iguales sino de aquello en lo que somos diferente. El Derecho no se nutre, pues, de la igualdad, sino de la diferencia.

Argumentos en favor de la calificación de la igualdad como derecho fundamental se extraen de otros ordenamientos. Así ocurre, ante todo, cuando acudimos a los ordenamientos constitucionales alemán y español, los cuales, como es sabido, califican la igualdad como derecho fundamental. 
No obstante por otra parte en la doctrina, se plantea que, más que un derecho de igualdad, lo que realmente existe es un derecho a no ser discriminado ${ }^{5}$. Puesto que en la práctica nadie reclama que se le conceda un trato igual a otro que está siendo tratado en forma más desfavorable; es lo que la Corte Constitucional Colombiana ha denominado "el perfil negativo del derecho de igualdad" (GÓMEZ, 2002).

Como apunta Boroswki en relación a los derechos de igualdad se debe a que también trata de fundamentar el derecho fundamental a la igualdad de la Constitución Alemana como un principio general de igualdad, en virtud del cual se puede demandar tanto la igualdad formal o de iure (igualdad en su faz negativa) como la igualdad material o de facto (igualdad en su faz positiva). Es por eso que nota que en virtud de dicho derecho, se puede demandar al Estado no sólo que omita conductas violatorias de la igualdad, sino que además, a través de su acción, satisfaga las exigencias fácticas que dicho derecho implicaría (FADIC, 2006, p.227).

\section{Igualdad como valor}

El concepto valor es utilizado de maneras muy diferentes, tanto en el lenguaje ordinario, como en el filosófico especializado. Los valores son potencialidades humanas que dignifican al individuo, constituyen un complejo y multifacético fenómeno que guarda relación con todas las esferas de la vida humana. Están vinculados con el mundo social, con la historia, con la subjetividad de las personas, con las instituciones. Existen múltiples definiciones acerca de los valores o de su papel en el Derecho, tales como que "los valores son criterios ideales en que lo jurídico tratan de orientarse, como supremas cualidades que se estima deben realizarse” (SICHES apud VECCHIO, p.158); “o cualidades sui géneris que poseen ciertos objetos llamados bienes, sin sustantividad propia, como meras posibilidades de un objeto" (FRONDIZI, 1993, p.4-7), y hasta desde posiciones conductistas se afirmó que el Derecho era regulador, plasmador de conductas seleccionadas luego de un juicio de valor.

Es un fenómeno complejo con manifestaciones distintas en diversos planos de análisis, coincido con José Remón Fabelo Corzo (2011, p.12) al plantear que los valores poseen un enfoque multidimensional, distinguiendo estas dimensiones como objetiva, subjetiva e instituida. Los valores son parte constitutiva de nuestra realidad social, cada objeto, fenómeno, suceso, tendencia, conducta, idea o concepción, desempeña una 
determinada función en la sociedad. No se trata de una dimensión trascendental e inamovible de los valores, sino de una objetividad social, dada por la relación funcional de significación del objeto o fenómeno dado con el ser humano. Para lograr que este criterio resulte aplicable será preciso que el valor de la igualdad, sea apreciado positivamente por el sujeto.

Un segundo plano, se refiere a la forma en que esa significación social, que constituye el valor objetivo, es reflejada en la conciencia individual y colectiva. En dependencia de los gustos, necesidades, intereses e ideales, pues cada sujeto social valora la realidad de un modo específico. Como resultado de este proceso de valoración, conforma su propio sistema subjetivo de valores. Esos valores subjetivos pueden poseer mayor o menor grado de correspondencia con el sistema objetivo, en dependencia, del nivel de coincidencia de los intereses particulares del sujeto dado con los intereses generales de la sociedad en su conjunto. Aprovecho la magistral posición del autor Osvaldo Alfredo Gonzain (1995, p.16) para mostrarte conteste a la hora de asumir una opinión doctrinal, en el sentido de que el valor de la igualdad no puede depender exclusivamente de un acto estimativo del sujeto, pues tal adaptación retorna a un sentir inadecuado, los valores no pueden depender del provecho que logremos, de ser así, caeríamos en un puro subjetivismo.

En la sociedad existen múltiples sistemas subjetivos de valores y cada uno de ellos juega un sistema regulador de la conducta. Si existiera la posibilidad de que cada sujeto actuase con absoluta libertad en atención a su sistema de valores subjetivos, nos encontraríamos en una sociedad anárquica, en la que cada uno haría lo que cree como correcto de acuerdo a la interpretación que tenga de lo valioso. Por esta razón los valores deben ser institucionalizados a partir de la política interna y externa, las normas jurídicas, la educación, así como otras vías. La dimensión instituida representa el ámbito fundamental donde se expresan los valores convertidos en normas jurídicas o en medios para el ejercicio del poder gubernamental.

El tratamiento de los derechos humanos, mostró desde su origen dos posiciones: una de índole eminentemente política y otra que asume el problema como una cuestión moral que engloba la totalidad del ser humano. El individualismo, propio de la ideología liberal, reduce los derechos de la libertad y la igualdad, limitando estos, a su vez, a la esfera de lo político. Esta deficiencia, consustancial a la concepción liberal moderna, dio lugar a que los 
derechos humanos fuesen vistos y tratados como una cuestión propia del derecho y de la política más que de la ética. De ese modo quedaba relegada, casi por completo, la perspectiva moral que insinuaba el tratamiento de los ideales. Por esta razón puede darse un nuevo enfoque a los derechos humanos desde una perspectiva moral, viendo a los mismos no solo como derechos sino como un valor alcanzado, superando de esta forma cualquier divorcio que pudiera existir entre la ética, la política y el derecho., pues el dinamismo que encierra tanto la realidad social como la formulación de los derechos humanos hacen que estos no sean abarcables únicamente como categoría jurídica, aunque formen parte del derecho positivo. Siendo la igualdad, una categoría ética, ya que expresa un valor fundamental que va más allá del ámbito de las normas meramente legales. Como bien expresa Luigi Ferrajoli al decir que "los fundamentos de los derechos humanos deben buscarse en valores como la igualdad, la democracia, la paz y el papel de los propios derechos como leyes de los sujetos más débiles dentro de una sociedad" (FERRAJOLI, 2009, p.15). Ya en la época de la Constitución de Weimar fueron sostenidas teorías axiológicas de los derechos fundamentales. Como bien expresa Robert Alexy al citar a Smend "el sentido concreto de un catálogo de derechos fundamentales reside en que pretende "normar una serie concreta, de una cierta unidad cerrada, es decir, un sistema de valores o bienes, un sistema cultural” (ALEXY, 1993, p.149). Por su parte, el reconocido jurista y filósofo Norberto Bobbio define a "la igualdad como valor supremo de una convivencia ordenada, feliz y civil, [...] como aspiración perenne de los hombres que viven en sociedad, y de otra, como tema constante de las ideologías y de las teorías políticas, [...]” (BOBBIO, 1993, p.53).

Por otra parte no solo se ve a la igualdad como un valor, sino que la misma constituye una línea directriz para el comportamiento humano, por tal razón se concibe como un principio rector del ordenamiento jurídico. De ahí que los principios y los valores estén estrechamente vinculados, ya que el cumplimiento gradual de los principios tiene su equivalente en la realización gradual de los valores. La comparación entre valor y principio puede apoyarse en algunas características estructurales y generales y, a la vez, elementales de los valores. Los principios deben ser ubicados en el ámbito deontológico (el ámbito del deber ser) y el otro en el ámbito axiológico (el ámbito de lo bueno).

Los significados de valor y principio que distinguen a la igualdad se encuentran estrechamente ligados, así lo afirma el Tribunal Constitucional Español desde su sentencia 8\1983, de 18 de febrero: “(...) la igualdad se configura como valor superior que, en lo que R. Fac. Dir. UFG, v. 38, n. 1, p. 119 - 141, jan. / jun. 2014 
ahora importa, se proyecta con una eficacia trascendente de modo que tal situación de desigualdad persistente a la entrada en vigor de la norma constitucional deviene incompatible con los valores de la Constitución (...)"

La igualdad en su carácter de valor es un regulador, por el que han de ser medidos y ordenados en la vida todos los fenómenos de la sociedad. Es un valor que tiene por objeto buscar el fundamento mismo de la convivencia, a cuyo fin el orden jurídico positivo se subordina a él, y los jueces que los interpretan encuentran una fuente modelo del cual no pueden apartarse sin caer en arbitrariedad o injusticia.

\section{Derecho Comparado}

La doctrina constitucional contemporánea nos enseña que en la mayor parte de las constituciones actuales el derecho de igualdad aparece consignado desde una triple óptica: en primer lugar es un valor, algo que se pretende alcanzar y que orienta toda la actividad tanto del Estado como de los particulares; en segundo lugar, la igualdad se concibe como un principio con carácter vinculante, y finalmente es también considerada como una regla, mandato concreto dentro del cual se subsume el caso concreto que se va a resolver.

La igualdad tiene una naturaleza polisémica o compleja que le asigna carácter de valor, principio o derecho. Una mirada rápida a la Constituciones modernas nos indica que al menos en la letra constitucional, se ha superado la exclusiva mención a la denominada igualdad formal o igualdad jurídica, que la burguesía vació de contenido, junto a ella aparece al menos teóricamente las otras dimensiones o planos de que hablamos anteriormente, configurándose la misma con un carácter trifonte; esto es como principio, como valor y como derecho subjetivo de naturaleza relacional o instrumental, como condición de ejercicio de los demás derechos.

Las diversas constituciones europeas toman inmediatamente este principioderecho para hacer énfasis de la igualdad del hombre ante la Ley o en su defecto han realizado desarrollos en las áreas en que la Declaración Universal de los Derechos Humanos ha puntualizado la igualdad. Por ejemplo, Alemania en su Constitución (Bonner Grundgsetz) de 1949, prevé en su artículo 3 el principio de la igualdad: “artículo 3 Todas las personas son iguales ante la ley. Los hombres y las mujeres tienen los mismos derechos. El Estado deberá R. Fac. Dir. UFG, v. 38, n. 1, p. 119 - 141, jan. / jun. 2014 
promover la aplicación efectiva de la igualdad de derechos para las mujeres y los hombres y las obras para la eliminación de las desventajas existentes. Ninguna persona por razón de sexo, parentesco, raza, idioma, patria y origen, la fe, la religión u opinión política o preferencia. Nadie podrá ser discriminado por motivo de su discapacidad"7.

Para determinar el contenido del principio y derecho de igualdad debemos remitirnos a lo desarrollado por la Constitución del Ecuador. La Constitución del 2008, es una Constitución moderna que incorpora las tendencias filosóficas modernas sobre el derecho. Por ejemplo partiendo del hecho que existe desigualdad en la realidad y que existen grupos vulnerables, en riesgo o en desigualdad la Constitución prevé mecanismos de "igualación" a favor de los desiguales.

De hecho la Constitución puntualmente se refiere al principio-derecho de igualdad en 36 artículos de los 444, desarrollando mecanismos de igualdad o equiparación de desigualdad modernos.

Para el Ecuador todas las personas son iguales, ya fueren ecuatorianos, extranjeros, naturales o jurídicas. La Constitución inclusive otorga esta igualdad a favor de ciertas abstracciones creadas por el asambleísta para que tengan capacidad de reclamar sus derechos, así lo son: las comunidades pueblos y nacionalidades, por ello de manera general se aplica la igualdad de manera objetiva y general a favor de la consideración del sujeto. Así cada uno de estos sujetos también está en capacidad de reclamar sus derechos (EGAS, p.107).

Por ello la segunda forma de aplicación del principio de igualdad desarrollado en la Constitución es la de igualdad de todos los derechos consagrados en la constitución, de tal forma que cualquiera de ellos (fuere de los considerados como fundamentales o no) puede ser exigible por igual, ante la justicia constitucional.

Es necesario también explicar que la igualdad pese a que es un derecho humano, en parte la Constitución lo ha desarrollado como principio de aplicación de los derechos, y en otros artículos como derecho en sí. Con esta intención me remitiré a los artículos en los la Constitución expresamente se ha remitido a la igualdad:

a) Igualdad como principio transversal. 
El artículo 11 de la Constitución dispone que el ejercicio de los derechos constitucionales, entre otros, se regirá por de igualdad y lo hace extensivo a sus derechos, deberes y responsabilidades e inmediatamente hace una prohibición extensiva a toda forma de discriminación.

Este mismo artículo incorpora a la norma constitucional la obligación del Estado de materializar la igualdad para hacer reales los derechos a favor de aquellas personas que se encuentran en una situación desigual. De esta manera no quedar en el enunciado de la igualdad formal (ante la Ley) sino de procurar una igualdad material (real) en la sociedad.

-Igualdad como principio aplicado al acceso a Medios de Comunicación e Información.

-Igualdad como principio aplicado a la Cultura y la Ciencia.

-Igualdad como principio de la Educación

-Principio de Igualdad quebrado por la diferenciación constitucional respecto de personas y grupos de atención prioritaria y determinación de tratos con prevalencia.

-Principio de igualdad aplicado a la equiparación de personas con discapacidad.

-Principio de Igualdad aplicado a las comunidades, pueblos y nacionalidades.

-Principio de Igualdad aplicado en los Derechos Políticos (De Participación).

-Principio de Igualdad aplicado al Acceso a la propiedad.

•Principio de igualdad aplicado al Régimen del Buen Vivir.

Sin embargo la jurisprudencia Peruana en innumerables sentencias ha señalado: "la igualdad, en tanto principio, es uno de los pilares del orden constitucional que permite la convivencia armónica en la sociedad" (TAIPICURI, 2012, p.59).

Por otro lado en la Constitución de la República de Cuba de 1976 la igualdad no aparece definido como valor aunque subyace en el de justicia social y el de bienestar individual y colectivo consagrado en el artículo 1.

Pero sí resulta claro, que es un principio, dos veces la cláusula del Capítulo VI (sexto) hace mención a ese atributo y como principio Constitucional, más bien como mega principio irradia a toda la letra de la Constitución. Se trata de un principio rector que ha de estar presente en el proceso de creación, aplicación e interpretación del Derecho. Aunque no 
se utiliza la expresión derecho a la igualdad, no cabe dudas que ostenta tal condición, pues los preceptos siguientes hacen referencia a la igualdad como parte del derecho que en ellos se consagra Ejemplo artículo 41: “Todos los ciudadanos gozan de iguales derechos y están sujetos a iguales deberes". 8

\section{Formas de Vulneración de la Igualdad}

El derecho de igualdad comporta un principio fundamental: las personas son iguales ante la ley y reciben un mismo trato y protección de la autoridades. El legislador en su papel de intérprete principal de la Constitución debe procurar por intermedio de las leyes que se establezcan las condiciones para alcanzar una igualdad real y efectiva entre todas las personas. Sin embargo, en algunos casos las leyes ocasionan una violación al derecho de igualdad por exceso o defecto o en otros casos, la igualdad resulta conculcada porque el legislador consagra en la ley privilegios injustificados en favor de sujetos determinados. Por último, la ley de forma explícita busca enmendar la situación de personas que históricamente han sido marginadas en este evento para alcanzar su equiparación con el resto de la sociedad, el contenido de la ley incluirá supuestos de discriminación positiva.

Entre las formas de vulneración al principio de igualdad se pueden mencionar:

- Exceso en la ley.

- Por defecto en la ley

- Privilegios injustificados concedido por la ley

- Posibilidad de discriminación positiva en la ley

- Tratamiento desigual del hombre y la mujer.

El exceso de las disposiciones legales que atenta contra el derecho de igualdad tiene lugar cuando en el texto de la ley, tomando como base las denominadas categorías peligrosas, sexo, nacionalidad, raza, religión, etc., se establecen unas consecuencias o condiciones sobre determinados sujetos aplicables sólo a ellos, y que se encuentran exclusivamente basadas en dichas categorías, de tal forma que al hacerlo se vulnera el derecho de igualdad.

La transgresión al derecho de igualdad también puede tener lugar por defecto de las disposiciones legales, esto es, cuando el precepto general de la ley comprende a un número 
menor de individuos de los que debería y deja por fuera a determinados sujetos que merecían haber sido incluidos en ella. De esta manera se crean inequidades y tratamientos discriminatorios por omisión de las leyes que marginan a ciertos grupos o individuos, quienes recibirán un tratamiento diferente a los demás por la exclusión indebida que de ellos hace la ley ${ }^{9}$.

Los privilegios injustificados tienen lugar cuando las disposiciones legales, usualmente contrariando las características de generalidad y abstracción, consagran beneficios o un trato preferente por determinados individuos o grupos sociales, claro está, sin que para ello exista una justificación razonable o una finalidad de equiparación de desigualdades materiales reales. Se trata, en definitiva, de una transgresión abrupta del principio de igualdad formal ante la ley, según el cual todas las personas son iguales ante la ley y reciben el mismo trato de las autoridades.

La discriminación positiva, que consiste en el tratamiento diferenciado que se les otorga a determinados grupos de individuos en atención a su condición sexual, física o por motivos de raza o cualquier otra de las denominadas categorías peligrosas ${ }^{10}$.

La vulneración del derecho de Igualdad, encuentra tutela además en el Código Penal cubano, en el Título IX Delitos contra los Derechos Individuales, Capítulo VIII Delito contra la Igualdad, artículo 295.1, que dispone: El que discrimine a otra persona o promueva o incite a la discriminación, sea con manifestaciones y ánimo ofensivo a su sexo, raza, color origen nacional o con acciones para obstaculizarle o impedirle, por motivos de sexo, raza, color u origen nacional, el ejercicio o disfrute de los derechos de igualdad establecidos en la Constitución, incurre en sanción de privación de libertad de seis meses a dos años de multa o de doscientas a quinientas cuotas o ambas.

2. En igual sanción incurre el que difunda ideas basadas en la superioridad u odio racial o cometa actos de violencia o incite a cometerlos contra cualquier raza o grupo de personas de otro color u origen étnico.

Cabe recordar que la reforma constitucional del año 1992, ensanchó las causas inmovilizadas de discriminación, adicionando creencias religiosas y la cláusula abierta que 
abarca cualquier otra lesiva a la dignidad humana, sin embargo el Código Penal, no fue modificado en tal sentido.

Como ha pronunciado el Tribunal Constitucional Español: "La igualdad (...) no constituye un derecho subjetivo autónomo, existente por sí mismo, pues su contenido viene establecido siempre respecto de situaciones jurídicas concretas. De ahí que pueda ser objeto de amparo en la medida en que se cuestione si tal derecho ha sido vulnerado en una concreta relación jurídica y, en cambio, no pueda ser objeto de una regulación o desarrollo normativo general”.

\section{Reflexiones finales}

Transitado por el complejo y muy discutido concepto de igualdad, en torno al cual han surgido desacuerdos teóricos importantes; constituyendo el mismo una demanda social, jurídica y política que se ha vuelto más exigente y compleja en la actualidad; y partiendo del análisis realizado en el presente artículo nos permitimos deslindar las conclusiones más puntuales sobre la regulación jurídica de la igualdad:

1. La igualdad requiere de la acción positiva para ser efectiva, la cual incluye una serie de medidas políticas, administrativas y legislativas. Por lo cual la configuración constitucional de la igualdad debe ser repensada, aún y cuando se establece su triple óptica.

2. Como derecho y principio se deben reforzar sus dos vertientes (igualdad ante la ley e igualdad en la ley), en pos de que los postulados que se refieran a la misma sean aplicados por los poderes públicos de manera correcta, y no persistan diferenciaciones injustificadas cuando de acceder a un servicio público o a la información se trata, propiciando de esta forma la igualdad de trato y de oportunidades.

3. Concebir la igualdad en la aplicación de la ley, favoreciendo de esta manera que todos los ciudadanos tengan acceso a la justicia, y así evitar que aún subsistan en la sociedad disposiciones sobre las cuales no cabe ulterior recurso.

4. La igualdad también implica la inclusión de todos los ciudadanos en la construcción de la sociedad, participando en la toma de decisiones políticas y económicas, logrando de esta manera un mayor grado de igualdad del administrado frente a la administración. 
5. La igualdad se debe concebir en el proceso de interpretación judicial, para evitar que se extralimite el carácter multidimensional del valor igualdad, pues una aplicación extrema del objetivismo puede llegar a un exceso del subjetivismo del juez, mayor del que obliga a sujetarse a la voluntad del legislador.

6. Se debe reforzar el sistema de garantías materiales y formales, conjugando de esta forma todas las vías institucionales y jurisdiccionales, en pos de que el ciudadano disfrute plenamente del derecho, principio y el valor de la igualdad.

\section{Legislación consultada}

Constitución de la República de Cuba de 24 de febrero de 1976, reformada en 1992 y en el 2002, Gaceta Oficial de la República, edición extraordinaria número 3 de 31 de enero 2003. Código Penal Cubano, Ley No.62 de 1987(actualizado) en Derecho Penal Especial Tomo III, Colectivo de Autores, Félix Varela (ed.), 2003, La Habana.

Constitución Monárquica Española de 1978.Civitas (ed.), Madrid, 1996.

Constitución de la República de Ecuador de 2008. Fondo de Solidaridad.

\section{Bibliografía}

ALARCÓN, Hugo M. Gónzalez. Análisis del Principio de Igualdad ante la doctrina y la jurisprudencia comparada. Disponible en:

$<$ http://www.revistajuridicaonline.com/images/stories/revistas-juridicas/derecho-publicotomo-6/87_a_122_analisis.pdf>

ALCALÁ, Humberto Nogueira. Teoría y Dogmática de los Derechos Fundamentales. México: Universidad Nacional Autónoma de México, 2003.

ALEXY, Robert. Teoría de los Derechos Fundamentales. Madrid: Centro de Estudios Constitucionales, 1993.

BOMBINO, Luis López. Por una nueva ética. La Habana: Editorial Félix Varela, 2006.

CARBONEL, Miguel. El principio constitucional de igualdad. México: Comisión Nacional de los Derechos Humanos, 2003.

CARBONEL, Miguel. Los derechos de igualdad en el constitucionalismo contemporáneo. Direitos Fundamentais. n.11. Justica, 2010.

CARBONEL, Miguel. Derechos Fundamentales y Democracia. México: Instituto Federal Electoral, 2013.

CARBONELL, Miguel. Igualdad y Constitución. México: Consejo Nacional para Prevenir la Discriminación, 2004. 
CARBONELL, Miguel. El pricipio de proporcionalidad y la interpretación judicial. Ecuador: Ministerio de Justicia y Derechos Humanos, 2008.

CARBONELL, Ricardo Ruiz. El principio de igualdad entre hombres y mujeres. Del ámbito público al ámbito jurídico familiar. Tesis como candidato a obtención al título de doctor. (En disco).

CORZO, José Remón Fabelo. Los valores y sus desafíos actuales. La Habana: Editorial José Martí, 2011.

EGAS, Jorge Zavala. Teoría y Práctica Procesal Constitucional. Guayaquil: Edilex S.A.

FADIC, Felipe Leiva. La deformación del Derecho Fundamental a la Igualdad. Un Argumento Contra de la Exigibilidad Directa de la Igualdad de Hecho. Revista de Estudios de Justicia. n.7. Chile: Facultad de Derecho, 2006. Disponible en:

<http://web.derecho.uchile.cl/cej/doc/LEIVA\%20_13.pdf>

FERNÁNDEZ, Albert Noguera. Los derechos sociales en las nuevas constituciones latinoamericanas. Editorial Tirant lo Blanch, VBlancha, 2010.

FERRAJOLI, L. et al. Los fundamentos de los derechos fundamentales. 4.ed. Madrid: Trotta, 2009.

FRONDIZI, R. Pensamiento axiológico. Antología. Prólogo, Epílogo y compilación por FABELO, J. R., Biblioteca Americana, La Habana-, 1993; p. 4-7, cfr. por Prieto Valdés Martha, El Derecho, la Constitución y la interpretación, p. 9.

GÓMEZ, Javier Ramírez. Violaciones al Derecho de Igualdad en la Ley Colombiana. Análisis Jurisprudencial. Revista. n.18. Colombia: Universidad del Norte, 2002. Disponible en: <http://rcientificas.uninorte.edu.co/index.php/derecho/article/viewFile/2975/2052>

GONZAIN, Osvaldo Alfredo. El derecho procesal constitucional y lo derechos humanos. México: Instituto de Investigaciones Jurídicas, 1995.

LAPORTA, Francisco J. El principio de igualdad: Introducción a su análisis. Revista de Ciencias Sociales. n. 67. Madrid: Editorial Sistema, 1985. Disponible en:

$<$ http://prontus.uv.cl/pubacademica/pubprofesores/z/pubzunigaalejandra/site/artic/20140514/a socfile/laporta_el_principio_de_igualdad_1985_.pdf>

LLORENTE, Francisco Rubio. La forma del poder. Estudios sobre la Constituición. Madrid: Centro de Estudios Constitucionales, 1993.

MELGAREJO, Rodrigo Brito. El principio de igualdad en el derecho constitucional comparado. Disponible en: <http://biblio.juridicas.unam.mx/libros/4/1968/9.pdf>

MIGUEL, Alfonso Ruiz. Sobre concepto de igualdad. México: Comisión Nacional de Derechos Humanos, 2003. 
MOSQUERA, Susana. Derecho a la Igualdad y medidas de garantías en el proyecto de la ley orgánica de igualdad. 2006. Disponible en:

<http://ruc.udc.es/dspace/bitstream/2183/2424/1/AD-10-39.pdf.>

PULIDO, Carlos Bernal. El Juicio de la Igualdad en la Jurisprudencia de la Corte

Constitucional Colombiana. Universidad Externado de Colombia. Disponible en:

$<$ http://portal.uexternado.edu.co/pdf/2_icrp/elJuicioDeLaIgualdadEnLaJurisprudencia.pdf.>

RABOSSI, Eduardo. Derecho Humanos: el Principio de Igualdad y la Discriminación.

Revista. n.7. Argentina: Centro de Estudios Institucionales, 1990.

ROYO, Javier Pérez. Curso de Derecho Constitucional. Barcelona: Marcial Pons Ediciones Jurídicas y Sociales S.A, 2005.

SICHES, Recasen apud VECCHIO; SICHES. Filosofía del Derecho. Estudios de Filosofía del Derecho. UTHEA. Mex. cfr. por Prieto Valdés Martha. El Derecho, la Constitución y la interpretación.

TAIPICURI, María Isabel Condezo. Vulneración de los derechos laborales en el régimen de contratación administrativa de los servicios. Lima Perú: Universidad Privada Norbert Wuiner S.A., 2012.

UBILLOS, Juan María Bilbao; MARTÍNEZ, Fernando Rey. El principio constitucional de igualdad en la jurisprudencia española. México: Comisión Nacional de Derechos Humanos, 2003.

VÁSCONEZ, José Joaquín Flor. S.J., Los Derechos Humanos de Personalidad. Quito: Cevallos Librería Jurídica, 2011.

VELÁZQUEZ, Manuel. La inspección del trabajo ante la igualdad de trato en el ámbito de las relaciones laborales. Disponible en: <http://www.upf.edu/iuslabor/_pdf/2006-

4/Administracion.pdf.>

1 "Parece que la justicia consiste en igualdad, y así es, pero no para todos, sino para los iguales; y la desigualdad parece ser justa, y lo es, en efecto, pero no para todos, sino para los desiguales"

${ }^{2}$ Igualdad matemática, la igualdad referida a personas y cosas que percibimos a través de los órganos de los sentidos.

${ }^{3}$ Declaración Universal de los Derechos Humanos:

Artículo 1

Todos los seres humanos nacen libres e iguales en dignidad y derechos y, dotados como están de razón y conciencia, deben comportarse fraternalmente los unos con los otros.

Artículo 7

Todos son iguales ante la ley y tienen, sin distinción, derecho a igual protección de la ley. Todos tienen derecho a igual protección contra toda discriminación que infrinja esta Declaración y contra toda provocación a tal discriminación.

${ }^{4}$ El artículo 6 de la Declaración de los Derechos del Hombre y del Ciudadano de 1789 señalaría el camino a lo que expone Miguel Carbonell: "La ley es la expresión de la voluntad general. Todos los ciudadanos tienen derecho a participar personalmente o a través de sus representantes en su formación. Debe ser la misma para todos, tanto si protege como si castiga. Todos, los ciudadanos, al ser iguales antes sus ojos, son igualmente admisibles a todas las dignidades, cargos y empleos públicos, según su capacidad y si n otra distinción que la de sus virtudes y talentos" 
${ }^{5}$ En materia internacional, a partir de la Declaración Universal de los Derechos Humanos de 10 de diciembre de 1948, y los Pactos tanto el de Derechos Civiles y Políticos como el de los Derechos Económicos, Sociales y Culturales, se han derivado varios Tratados Internacionales dirigidos a prohibir distintas formas de discriminación. Entre los tratados internacionales que prohíben formas de discriminación, vale citar: la Convención sobre los Derechos Políticos de la Mujer (Nueva York, 31 de marzo de 1953), el Convenio sobre la eliminación de todas las formas de discriminación contra la mujer (Nueva York, 18 de diciembre de 1979), el Convenio sobre la eliminación de todas las formas de discriminación racial (Nueva York, 7 de marzo de 1966), los Convenios de la OIT sobre la igual remuneración entre la mano de obra masculina y la mano de obra femenina por un trabajo de igual valor (núm.10, 29 de junio de 1951), y sobre la discriminación en materia de empleo y profesión (núm., 111, 25 de junio de 1958), la Convención de la UNESCO relativa a la lucha contra las discriminaciones en la esfera de la enseñanza (14 de diciembre de 1960).

${ }^{6}$ Sentencia de suma importancia en el análisis del criterio jurisprudencial que ha mantenido el Tribunal Constitucional Español en relación con el principio de igualdad y su carácter de valor. Tomado de Hernández Martínez María del Pilar. El principio de igualdad en la jurisprudencia del Tribunal Constitucional Español, pdf, p. 3.

7 Flor Vásconez, José Joaquín S.J., "Los Derechos Humanos de Personalidad", Cevallos Librería Jurídica, Quito, 2011, p.422. Cita la Constitución Deutscher Bundestag.- (Constitución Alemana).- Artículo 3. http://www.bundestag.de/dokumente/rechtsgrundlagen/grundgesetz/index.html 25/04/2011.

${ }^{8}$ Constitución de la República de Cuba 1976.

${ }^{9}$ Méndez Josefina, Cutié Danelia, La Cláusula de la Igualdad. Una relectura a 33 años de la Constitución Cubana p 10, (en disco). Donde se precisa que, al revisar el Código Penal Ley No.62 de 1987, se aprecia el criterio sexista que sigue en torno al los delitos contra la libertad sexual (Delitos contra el normal desarrollo de las relaciones sexuales), así mantiene la diferencia en los hechos en que el sujeto pasivo es una mujer o un hombre, para el primero de los cuales regula el delito de violación y para los segundos el de pederastia con violencia, distinción que en otras legislaciones se ha fundido en un único tipo penal que denominan agresiones sexuales, de esta forma no sólo elimina la desigualdad entre ambos sexos en la legislación penal, sino que abre la protección hacia otros supuestos que hoy se imponen ante los cambios que ocurren en la sociedad, como puede ser la agresión sexual a los transexuales.

El trato desigual se hace notar aún más en la referida legislación penal, cuando en una figura agravada, se establece un mayor marco penal en relación con la edad de la víctima, estableciendo para la violación la edad de 12 años en la mujer (artículo298.4) y en la pederastia el varón menor de 14 años, apreciándose un criterio de discriminación que se basa en concepciones biológicas, ya superadas por las corrientes que defienden el enfoque de género.

${ }^{10}$ Resulta también polémico el tratamiento que la Ley de Procedimiento Civil, Administrativo, Laboral y Económico, Ley No.7 de 1977, artículo 586, ofrece a las personas con sordomudez al establecer como causa o razón para la declaración de incapacidad, la enajenación mental y la sordomudez, por lo que en tal sentido dichas personas carecerían de plena capacidad para ejercer sus derechos, y se les deberá nombra tutor.; lo cual evidencia el rezago de la ley de trámites, al considerar a la altura de estos tiempos, con los avances científicos en materia educacional y de salud que existen en el país, que las personas con discapacidad por limitaciones auditivas, son incapaces para ejercer sus derechos, colocándolos en situación desventaja social, pudiendo quedar disminuido, con esa declaración el derecho a la igualdad de los mismos.

Categorías peligrosas se pueden encontrar en el artículo 42: La discriminación por motivo de raza, color de la piel, sexo, origen nacional, creencias religiosas y cualquiera otra lesiva a la dignidad humana está proscrita y es sancionada por la ley. 